\title{
A Pandemia e a precarização das condições de trabalho dos docentes de ensino superior
}

\author{
The Pandemy and the precarization of working conditions of higher education teachers \\ La Pandemia y la precarización de las condiciones laborales de los profesores de educación
} superior

Recebido:17/07/2021 | Revisado: 20/07/2021 | Aceito: 20/07/2021 | Publicado: 23/07/2021

\author{
Alessandra Dale Giacomin Terra ${ }^{1}$ \\ ORCID: https://orcid.org/0000-0003-3311-121X \\ Universidade Federal Fluminense, Brasil \\ E-mail: alessandragterra@gmail.com \\ Thiago Guerreiro Bastos ${ }^{2}$ \\ ORCID: https://orcid.org/0000-0002-4070-610X \\ Universidade Estácio, Brasil \\ E-mail: thiagoguerreirobastos@gmail.com \\ Lílian Cazorla do Espírito Santo Nunes ${ }^{3}$ \\ ORCID: https://orcid.org/0000-0001-5314-8672 \\ Universidade Estácio, Brasil \\ E-mail: liliancazorla@gmail.com \\ Bárbara Terra Queiroz ${ }^{4}$ \\ ORCID: https://orcid.org/0000-0002-2784-5498 \\ Secretaria de Educação do Estado do Espírito Santo, Brasil \\ E-mail: bterra.queiroz@gmail.com
}

\begin{abstract}
Resumo
O presente texto busca pontuar e refletir sobre alguns dos impactos da Pandemia de COVID-19 no âmbito das condições de trabalho dos docentes de nível superior no Brasil. Com a necessidade de isolamento social e a impossibilidade de manutenção das aulas em regime presencial, migrou-se o ambiente de ensino-aprendizagem para o formato online, o que vem implicando (e evidenciando) uma precarização não só do ensino, como também das condições de trabalho dos professores, cada vez mais sobrecarregados. Esta pesquisa foi desenvolvido por meio pesquisa qualitativa, com análise de documentos oficiais e revisão de literatura. Este estudo se justifica pela necessidade de se refletir sobre as profundas mudanças impostas pela pandemia e seus efeitos sobre a qualidade do ensino-aprendizagem e as condições de trabalho docente.
\end{abstract}

Palavras-chave: Ensino superior; Precarização; Condições de trabalho; Direito do Trabalho; Pandemia.

\begin{abstract}
This text seeks to point out and reflect on some of the impacts of the COVID-19 Pandemic on the working conditions of higher education teachers in Brazil. With the need for social isolation and the impossibility of maintaining classroom classes, the teaching-learning environment was migrated to the online format, which has been implying (and evidencing) a precariousness not only of teaching, but also of conditions teachers' workload, increasingly overloaded. This research was developed through qualitative research, with analysis of official documents and literature review. This study is justified by the need to reflect on the profound changes imposed by the pandemic and its effects on the quality of teaching-learning and teaching work conditions.
\end{abstract}

Keywords: Higher education; Precariousness; Work conditions; Labor law; Pandemic.

\section{Resumen}

Este texto busca señalar y reflexionar sobre algunos de los impactos de la pandemia COVID-19 en las condiciones laborales de los docentes de educación superior en Brasil. Con la necesidad de aislamiento social y la imposibilidad de mantener las clases presenciales, el entorno de enseñanza-aprendizaje se migró al formato online, lo que ha venido

\footnotetext{
${ }^{1}$ Doutoranda em Ciências Jurídicas e Sociais pelo Programa de Pós-Graduação em Sociologia e Direito da Universidade Federal Fluminense e Bolsista da Coordenação de Aperfeiçoamento de Pessoal de Nível Superior (CAPES).

${ }^{2}$ Doutor em Finanças Públicas e Desenvolvimento do Programa de Pós-Graduação em Direito (PPGD/UERJ), Professor do curso de Direito da UniCarioca e do curso de Direito da Universidade Estácio.

${ }^{3}$ Doutora pelo Programa de Pós-Graduação em Sociologia e Direito (PPGSD/UFF) e Professora do curso de Direito da UniCarioca e do curso de Direito da Universidade Estácio.

${ }^{4}$ Mestre pelo Programa de Pós-Graduação em Arquitetura (PROARQ/UFRJ) e Professora do Ensino Técnico do Estado do Espírito Santo.
} 
implicando (y evidenciando) una precariedad no solo de la docencia, sino también de las condiciones de carga de trabajo de los docentes, cada vez más sobrecargado. Esta investigación se desarrolló a través de una investigación cualitativa, con análisis de documentos oficiales y revisión de la literatura. Este estudio se justifica por la necesidad de reflexionar sobre los profundos cambios impuestos por la pandemia y sus efectos sobre la calidad de la enseñanzaaprendizaje y las condiciones de trabajo docente.

Palabras clave: Enseñanza superior; Precariedad; Condiciones de trabajo; Directo del trabajo; Pandemia.

\section{Introdução}

O presente texto busca pontuar e refletir sobre alguns dos impactos da Pandemia de COVID-19 no âmbito das condições de trabalho dos docentes de nível superior no Brasil. Com a necessidade de isolamento social e a impossibilidade de manutenção das aulas em regime presencial, migrou-se o ambiente de ensino-aprendizagem para o formato online, o que vem implicando (e evidenciando) uma precarização não só do ensino, como também das condições de trabalho dos professores, cada vez mais sobrecarregados.

O ensino superior não presencial é uma realidade no Brasil desde o final da década de 1990, com a Lei de Diretrizes e Bases da Educação Nacional (Lei $n^{\circ}$ 9.394, de 1996). Nota-se que a ampliação do formato à distância atende a interesses corporativos de redução de custos, e é usualmente justificada por meio de proposta pedagógica formal, com referências à pedagogia freireana. Fundamenta-se redução de carga horária na adoção de "metodologias ativas", e jargões como "o aluno deixou de ser um depositário de conteúdo e que agora é protagonista do seu próprio saber". Cumpre esclarecer que, nesta sede, não se nega a virada pedagógica e a importância de Paulo Freire para o desenho da educação no Brasil. Na verdade, o que se critica é a forma como essa proposta que impõe mudança de paradigma cultural e do ambiente da sala de aula, muitas vezes mais com a finalidade de reduzir a carga horária das disciplinas e gastos com remuneração de professores, em vez de verdadeiramente reformular a forma de ensinar e aprender.

O ambiente escolar, independentemente do nível de ensino, propicia, ainda, trocas sociais e força à vivência em um espaço público plural no qual o educando tem acesso a diversas visões de mundo e realidades socioeconômicas distintas da sua. O espaço físico, diferente do ambiente virtual, transforma pelo simples contato com o outro.

Este estudo se justifica pela necessidade de se refletir sobre as profundas mudanças impostas pela pandemia e seus efeitos sobre a qualidade do ensino-aprendizagem e as condições de trabalho docente.

\section{Metodologia}

Esta pesquisa foi desenvolvida por meio pesquisa qualitativa, com método hipotético-dedutivo (Nevado, 2008), através da análise da documentação empírica (Cardano, 2017) e revisão de literatura.

\section{Resultados e Discussão}

\subsection{Desprofissionalização Docente}

O modelo de ensino não presencial não chega a ser uma novidade no ensino superior, mas a adoção integral do formato online trouxe dinâmicas as quais docentes, discentes e instituições de ensino superior (IES) não estavam preparados, nem em termos tecnológicos, nem pedagógicos.

O Ensino a distância (EAD) no nível superior emergiu no Brasil no final dos anos 1990 e vem desde então se intensificando, afetando diretamente as condições de trabalho dos docentes. O ensino em formato a distância já existiu em diversos formatos, como pela televisão, correio e radio, mas ganhou folego com o avanço da internet. Dos marcos legais sobre EAD no Brasil devemos destacar a Lei de Diretrizes e Bases da Educação Nacional n 9.394, de 1996, que dedicou um artigo ao ensino a distância e foi regulamentado Decretos n 2.494 de 10/02/98, que autorizou a constituição dos cursos a distância no 
Brasil em nível de graduação, até ser revogado pelo Decreto $n^{\circ} 5.622$ de 2005, que por sua vez foi revogado pelo Decreto $\mathrm{n}^{\circ}$ 9.057, de 2017. Já a Portaria n ${ }^{\circ}$ 1.428, de 28 de dezembro de 2018 autorizou a oferta de $20 \%$ da carga horária na modalidade EAD em cursos de graduação presenciais, emergindo no ensino superior o que foi denominado de ensino "híbrido" (ensino presencial com parcela da carga horária online). Em 2019, a Portaria № 2.117 do Ministério da Educação (MEC) ampliou o limite para $40 \%$.

A ampliação do formato à distância atende a interesses corporativos de redução de custos, aumentando a margem de lucro, e é usualmente justificada por meio de proposta pedagógica formais, com referências à pedagogia freireana. Fundamenta-se redução de carga horária na adoção de metodologias ativas, e jargões como "o aluno deixou de ser um depositário de conteúdo e que agora é protagonista do seu próprio saber”. Não se nega a virada pedagógica e a importância de Paulo Freire, mas se critica a forma como essa proposta que impõe mudança de paradigma cultural e do ambiente da sala de aula, muitas vezes mais com a finalidade de reduzir a carga horária das disciplinas e gastos com remuneração de professores, do que reformular o modo de ensinar e aprender.

Na prática, contudo, o aluno não lê o material elaborado, nem debate. Sequer comenta ou pergunta, apenas aguarda que o professor the entregue o conteúdo da aula, como se fosse um produto que acabou de comprar e aguarda receber. A dinâmica entre professor-aluno e a expectativa do alunado na prática é muito diversa da do aluno protagonista, e muito mais próxima do aluno consumidor adepto da pedagogia "bancária" passiva (Freire, 1994, p. 39).

Essa alteração abrupta sem qualificar o professor e sem estimular alteração comportamental dos discentes é nociva e ineficaz, ao menos do ponto de vista didático, apesar das benéficos em termos de gestão e redução de custos. O ensino se precarizou tão rapidamente quanto as condições de trabalho dos professores. A pandemia que se iniciou na China no final de 2019 ganhou novas dimensões nos primeiros meses de 2020. Em março, todos deixamos o ambiente físico crendo que o isolamento preventivo que se iniciava duraria no máximo algumas semanas. Estávamos, sobretudo, iludidos e otimistas.

Ainda hoje, o panorama acerca do retorno às aulas presenciais é nebuloso. O que se percebe é uma profunda transformação no ambiente da educação superior nos últimos meses, e não se vislumbra reestabelecimento do cenário anterior nem mesmo diante de uma possível vacinação em massa ao longo de 2021 .O objetivo aqui não é discutir qual nível de ensino tem sofrido mais ou menos com a pandemia, mas apenas analisar os elementos da mudança no ambiente do ensino superior e o que isto significa e pode significar em termos de condições de trabalho.

Convém ressalvar que o ensino superior havia aderido parcialmente ao Ensino à Distância (EAD) por meio da criação dos chamados cursos híbridos por meio dos quais parte da carga horária do ensino presencial se efetivava por meio de aulas online (síncronas ou assíncronas). Isso reflete, na verdade, uma técnica de gestão de inclusão de tecnologia com objetivo de reduzir custos e aumentar lucro dos institutos de ensino superior. Alega-se, contudo, que a mudança se faz necessária para adaptação dos métodos de ensino e da sala de aula para a nova geração que tem mais familiaridade com tecnologia e ambiente virtual.

O discurso reiteradamente empregado é de que passamos por inserção de tecnologias e novas pedagogias que fariam com que o aluno deixasse de ser um depositário de conteúdo para assumir uma postura mais ativa no próprio processo de aprendizagem. $\mathrm{O}$ ensino à distância tem se valido bastante desse fundamento para atribuir ao aluno papel central do estudo de modo autodidata. Ademais, é inegável que o avanço tecnológico, o barateamento dos custos de internet e outras ferramentas impulsionam o EAD que se utiliza das metodologias ativas para oferecer um processo de ensino-aprendizagem supostamente mais dinâmico e que potencializa o desenvolvimento de certas habilidades valorizadas pelo mercado de trabalho.

No entanto, nos termos do artigo 205 da Constituição Federal de 1988, que versa sobre o direito fundamental social à educação, observa-se que o sentido conferido ao "educar" extrapola o conceito de preparar alguém para o mercado de trabalho; educar é transformar, é desenvolver plenamente as potencialidades do indivíduo e permitir que ele assume as rédeas da 
construção da sua própria individualidade à luz da dignidade da pessoa humana. Educar, antes de qualificar uma mão de obra, é formar um cidadão e o tornar apto ao debate público em razão de uma visão de mundo mais crítica e científica.

$\mathrm{O}$ ambiente escolar, independentemente do nível de ensino, propicia, ainda, trocas sociais e força à vivência em um espaço público plural no qual o educando tem acesso a diversas visões de mundo e realidades socioeconômicas distintas da sua. O espaço físico, diferente do ambiente virtual, mitiga certos pontos-cegos que todos nós temos pelo simples fato de conhecer o outro. Ironicamente, nestes meandros em que o ideário de Paulo Freire (2002) é acionado como mecanismo de legitimação para atribuir ao aluno papel central do estudo de modo autodidata, a proposta de educação transformadora é obliterada.

A tecnologia em si não é o problema. Sua inserção no ambiente educacional não degrada a didática ou as condições de trabalho docentes. Ela inclusive pode ser instrumento potencializador dos níveis de aprendizagem se vier a ser utilizado com esse objetivo. O que se pretende chamar atenção neste trabalho é que o empresariamento da educação vem resultando em uma dinâmica de busca por lucro, que leva que o tecnológico seja encarado como método de barateamento de custo, redirecionando o ônus para os professores, afetando suas condições de trabalho de forma negativa.

É importante destacar que este processo é um desdobramento da mercantilização do ensino superior após os anos 1990. Em 1996 a Lei de Diretrizes e Bases da Educação Nacional (LDB), em 1996, passou a autorizar que as IES privadas do país pudessem ter fins lucrativos e flexibilizou seus regimes jurídicos, permitindo que se constituíssem como Sociedade Anônimas de capital aberto (Lima, 2019).

Com o avanço do EAD, também vem sendo rediscutido o conceito e identidade do professor (Neves \& Fidalgo, 2016), que agora passa a ser nomeado de facilitador e mediador. A docência virtual é complexa e é em situações normais desempenhada por docentes-autores (conteudista), assim como docentes-formadores (coordenador da disciplina e tutores) (Neves \& Fidalgo, 2016). Durante a pandemia os professores vêm desempenhando todos estes papéis concomitantemente, em regra sem auxílio ou remuneração extra.

Conforme Neves e Fidalgo (2016) as transformações decorrentes da inserção de tecnologia vem modificando profundamente o processo de trabalhado do professor, e conjugadas com a falta de regulamentação da carreia de docente virtual, vem implicado em desprofissionalização, circunstância que considera análoga a de subproletariado e aponta que no caso brasileiro a maioria das contratações ocorre sem vínculo trabalhista por meio do pagamento de bolsas. Podemos acrescentar que mais recentemente isso também vem se dado por meio de pejotização, uma forma de se deturpar uma relação de emprego, formalmente fazendo-a aparecer uma situação jurídica de natureza civil, como um contrato de locação de mão de obra ou de empreitada, e que implica numa precarização da relação de trabalho por resultar na supressão/mitigaçção de uma série de direitos trabalhistas, como férias, $13^{\circ}$ salário, FGTS, descanso remunerado, entre outros. Conforme Oliveira (2013, p. 25), "a denominação é fruto da sigla da pessoa jurídica, isto é, PJ = pejotização, a 'transformação'do empregado (sempre pessoa física) em PJ (pessoa jurídica)."

\subsection{A pandemia e as transformações no ensino superior}

O professor digital tem demandas multidisciplinares. Além de prepara o conteúdo, editar vídeos, tornou técnico de informática (soluciona e indica soluções para conexão própria e dos alunos) e em algumas instituições privadas passou a ter de realização atividades de apoio administrativo (tentando captar e manter as matrículas dos discentes ativas). Portanto, os desafios da docência na e pós-pandemia vão muito além da inserção tecnológica; envolve também a precarização do docente e do ensino. 
Não houve tempo, nem capacitação dos professores em metodologias pedagógicas pensadas para o ensino online, que é pensado desconsiderando as especificidades dos alunos, sejam condições econômicas, dificuldades cognitivas, distúrbios de aprendizagem e as necessidades de pessoas com deficiências.

A atividade docente inclui uma série de atividades invisibilidades e muitas vezes ignoradas no computo remuneratório. Além das atividades de preparação de aula, correção/elaboração de provas, ao magistério superior é imprescindível a realização de atividades de pesquisa, ainda que as faculdades e centros universitários não tenham obrigação de fazê-lo. Progressivamente os regimes de trabalho vêm sendo convertidos a horistas, em que se remunera as horas-aula ministradas. Com a pandemia e o formato online, a situação se agrava, pois, a jornada ganha uma maior fluidez e indeterminação, que vão sendo invadidas pelas mensagens de alunos e colegas mediante redes sociais privadas. Também se teve uma ampliação da carga horária informal de trabalho do professor, com aumento de atividades administrativas, invadindo horários de descanso e fins de semana. A pandemia fez com que o MEC autorizasse que atividades educacionais não presenciais fossem computadas para a integralização da carga horária letiva (MEC, 2020). Enquanto, as faculdades privadas migraram em poucas semanas para a modalidade remota, as instituições públicas de ensino superior suspenderam suas atividades.

De acordo com o Censo da Educação Superior feito em 2018 (INEP, 2019), há no Brasil 2.537 IES das quais 2.238 são privadas e 299 são públicas. O levantamento também identificou que o número de ingressantes em cursos de graduação a distância vem aumentando substancialmente, passando de 20\% (vinte por cento) em 2008 para 40\% (quarenta por cento) em 2018, conforme pode-se visualizar no gráfico abaixo.

Gráfico 1: Número de vagas presenciais e a distância dos cursos de graduação.

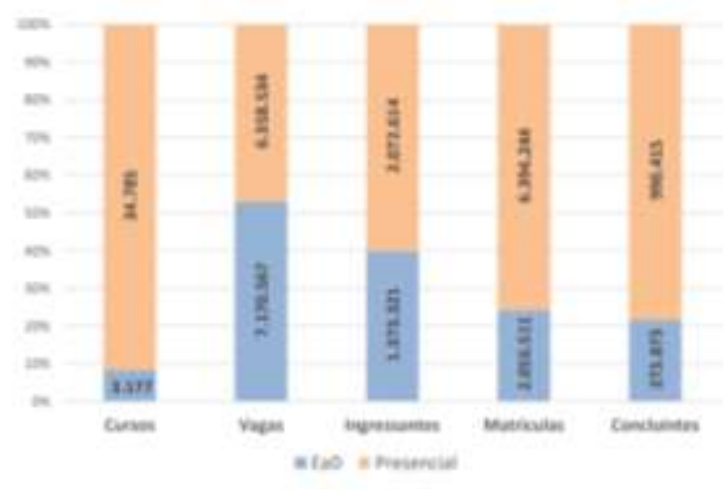

Fonte: MEC/Inep; Censo da Educação Superior (2018).

Apenas o avanço tecnológico e a demanda das novas gerações pela modernização do ensino não explicam o crescimento do modelo à distância. Na prática, o aumento identificado pelo censo tem relação com a redução de custos (espaço físico, salário de docente, entre outros) e não pela potencialidade de um suposto ensino dinâmico. Para o SEMESP (2020), contudo o modelo remoto de aula digital não seria, necessariamente, aquilo que conhecemos como EAD, considerando que o ensino com aulas remotas-síncronas (ao vivo) seriam "como conexão do presencial com a casa do aluno", e que estas se diferenciariam do tradicional modelo EAD, uma vez que neste há mediação por tutores e os conteúdos são gravados e aproveitados em larga escala, o que implica em menores custos, enquanto naquele utiliza-se aulas adaptadas com a mesma estrutura das aulas presenciais e a mesma dedicação integral dos professores. O SEMESP no website "O Valor da Educação", por ele patrocinado destaca que: 
O Ensino à Distância, ou EaD, é uma modalidade de educação e aprendizagem já pensada de forma a contar com recursos tecnológicos, como transmissão de dados via internet, para a condução do currículo de estudos.

Os professores gravam suas aulas e propostas de exercícios, que são disponibilizados de forma sistemática para os alunos, muitas vezes tendo interação com tutores via chat ou e-mail e horários agendados com professores para sanar dúvidas.

Isso difere muito do Ensino Remoto que tem sido praticado emergencialmente por muitas instituições. Na prática, isso significa apenas uma transferência do conteúdo ministrado presencialmente para o ambiente virtual ou de videoconferências. A estrutura teve de ser rapidamente adaptada, com investimentos em capacitação profissional e ferramentas específicas para este tipo de ambiente, em que professores e alunos podem interagir, mesmo que em espaços diferentes, seguindo uma programação que possa favorecer a troca, com ambos em contato em tempo real, mantendo a interação professor $\mathrm{X}$ aluno como no curso presencial.

É essa diferença primordial que está criando um espaço grande entre o andamento do EaD e do Ensino Remoto: em um, há a expertise necessária e um investimento condizente com a prática; em outro, um gasto excessivo com adaptações para um formato para o qual não se tinha, anteriormente à pandemia, o preparo adequado" ( $O$ valor da educação, 2020, n.p)

No mesmo sentido se posicionou a ADUP (2020), apontando que o ensino não-presencial que vem sendo realizado atualmente pelas instituições de ensino através da internet não se trata de EAD, mas sim de ensino remoto, em razão de ocorrerem de forma síncrona (ao vivo):

Segundo a legislação brasileira, a educação à distância é caracterizada pela diversidade de tempo e espaço. Ou seja, as aulas que acontecem ao vivo, com estudantes e professores interagindo ao mesmo tempo, descaracterizam a educação a distância. Aulas síncronas, são consideradas, assim, presenciais mediadas por tecnologias ou também chamadas de tele-presenciais (ANUP, 2020)

Tendo em vista que a fonte de custeio da rede privada é a cobrança de mensalidade, fica, portanto, evidente, que o setor passa por dificuldades em razão dos desdobramentos econômicos que atingiram os discentes. De acordo com uma pesquisa realizada pelo Sindicato das Entidades Mantenedoras de Estabelecimentos de Ensino Superior no Estado de São Paulo (SEMESP) houve aumento de 71,1\% (setenta e um por cento) na taxa de inadimplência e 11,5\% (onze por cento) na taxa de evasão em abril de 2020, isto é, cerca de um mês após o início da pandemia, quando comparado com o mesmo período do ano anterior. Como considerável parcela dos estudantes teve sua renda afetada pela crise do COVID-19, houve aumento da taxa de inadimplência e, consequentemente, de evasão. Surgiram demandas dos discentes pela redução das mensalidades, tanto de forma casuística, negociando diretamente junto às instituições, como pedidos de redução linear, ou seja, na mensalidade de todos os alunos. Exemplo disso foi o abaixo assinado com mais de cinquenta mil assinaturas organizado pela União Nacional dos Estudantes (UNE), que pedia ao Ministério Público Federal a abertura de uma ação coletiva. Os estudantes também vêm buscando órgãos de defesa do consumidor (G1; 2020; G1; 2020b; Agência Brasil; 2020).

Diversas instituições privadas e entidades representativas destas se posicionaram no sentido da irredutibilidade dos valores das mensalidades, lançando a campanha "O valor da Educação" e sustentando que apesar da suspensão das atividades presenciais, não houve redução dos gastos e que algumas instituições tiveram, na verdade, um aumento com instalação de novos equipamentos tecnológicos para transmissão e a aquisição de licenças de uso de novas ferramentas digitais, e que as atividades persistem por meio remoto. Além disso, estimam que haverá um aumento de gastos com a retomada das atividades: “retomada das atividades, como já está ocorrendo em alguns países da Europa, obrigará as IES a adotar medidas que aumentarão ainda mais seus custos, para garantir que a frequência às aulas presenciais obedeça ao necessário distanciamento social e minimize o risco de contágio" (SEMESP, 2020, n.p).

Outra justificativa para a não redução das mensalidades das faculdades privadas seria o impacto econômico da pandemia no setor de educação superior, sob fundamento de que a redução agravaria a problemática levando à falência de universidades privadas e à demissão de professores: 
Um estudo realizado pelo Instituto Semesp, com 1.257 instituições de todo o país, revela que mais de $21 \%$ das IES poderão não ter condições de pagar a folha de pagamento do mês de maio e 39\% amargarão prejuízo superior a $20 \%$ da receita líquida em 2020, por conta do aumento da evasão e da inadimplência no atual período. O mais preocupante no estudo é a indicação de que, diante de uma redução horizontal de $30 \%$ das mensalidades, cerca de $30 \%$ das instituições terão de fechar as portas ainda no ano de 2020 (SEMESP, 2020, n.p).

A ADUP (2020) chama atenção para a necessidade de que professores e estudantes tenham equipamentos e internet em suas casas, porém esta não é a realidade de uma parcela considerável de estudantes neste país. Segundo a pesquisa TIC Domicílios (2018) apenas 67\% (sessenta e sete por cento) dos domicílios têm acesso à internet, sendo que 56\% (cinquenta e seis por cento) dos usuários da rede no Brasil estão conectados à rede apenas pelo celular, ou seja, sem acesso a equipamentos necessários a um ensino remoto. Além disso, apenas 40\% (quarenta por cento) dos domicílios das classes D/E estão conectados.

Desse modo, a um só tempo se reconfiguraram o espaço físico da sala de aula e também a relação docente-discente. O discurso se apoia no papel de intermediador do professor, como facilitador do acesso ao saber e não mais como detentor de um monopólio cultural e educacional. $\mathrm{O}$ aluno não é mais visto como um objeto a ser formado, não é mais um ser que demanda iluminação, mas sujeito ativo da construção do seu próprio saber. O protagonismo docente passa a dividir espaço com a iniciativa discente na própria formação por meio da razão; é como se todo o saber fosse inato ou estivesse ao alcance de todos. Alcançar esses novos níveis de aprendizagem dependem, portanto, de um sujeito mais ativo (Freire, 2002, p. 13).

A Associação Nacional das Universidades Particulares - ANUP, disponibilizou orientações para as IES privadas, de como se adaptar ao ensino remoto durante a pandemia, ressalvando que "digitalizar a educação envolve processos de gestão como inscrição, certificação a processos de elaboração de conteúdos, armazenamento e compartilhamento e processos de interação professor-aluno" (ANUP, 2020). No ambiente digital atribui-se ao professor o dever de gestão do material ali disponibilizado, ou seja, deve produzir, fazer upload, manter, atualizar e fiscalizar o andamento do espaço virtual sob sua responsabilidade. Estes documentos são essenciais para viabilizar que o aluno tenha acesso a conteúdo extra para ampliar e aprofundar seu próprio processo de aprendizagem. Estes admitem o compartilhamento de materiais didáticos por meio de texto escrito, vídeos, questionários, atividades extracurriculares, imagens, além de ser um canal possível para propositura de tarefas, fóruns de discussão, entre outras práticas que viabilizem o saber. Apesar de falar sobre ferramentas para criação de conteúdo, o referido texto da ANUP (2020) não chama atenção para o trabalho do professor de criação dos mesmos, ou menciona a necessidade de participação de tutores ou mediadores para auxiliá-lo. Também não faz esclarecimentos sobre propriedade intelectual.

\subsection{Professor online é o novo normal?}

Pesquisa da ABMES promovida pela Educa insights (2020) destacou que a aceleração do ensino à distância é um legado da crise do Coronavírus. Houve aumento na sua aceitação. Atualmente, cerca de 67\% (sessenta e sete) por cento dos alunos avalia a sua experiência com o EAD como positiva, porém 73\% (setenta e três por cento) prefere o ensino presencial, enquanto $24 \%$ (vinte quatro por cento) consideraria ambos os formatos e $3 \%$ (três por cento) migraria totalmente para a modalidade EAD. A mesma pesquisa aponta que a 63\% (sessenta e três por cento) das aulas dos alunos entrevistados vêm sendo realizadas em formato síncrona, $9 \%$ (nove por cento) assíncrona e $28 \%$ (vinte oito por cento) nos dois formatos. A pesquisa realiza uma projeção, considerando o cenário de retração de renda e emprego, prevendo que haverá aumento de novas matrículas no EAD maior que em relação à modalidade presencial.

Outra pesquisa de tais entidades (2018), em que se analisava o impacto do Decreto $\mathrm{n}^{\circ}$ 59.057/2017 (que permitiu a ampliação do EAD no ensino superior), projetou um aumento do EAD que iria superar o presencial em 2022 (Gráfico 2). 
Gráfico 2: Crescimento de cursos de graduação EAD.

\section{ABMES \\ PESQUISA \\ veis mis \\ Se ambas as modalidades mantiverem as atuais taxas de crescimento anual, a EAD irá superar o presencial em 2023}

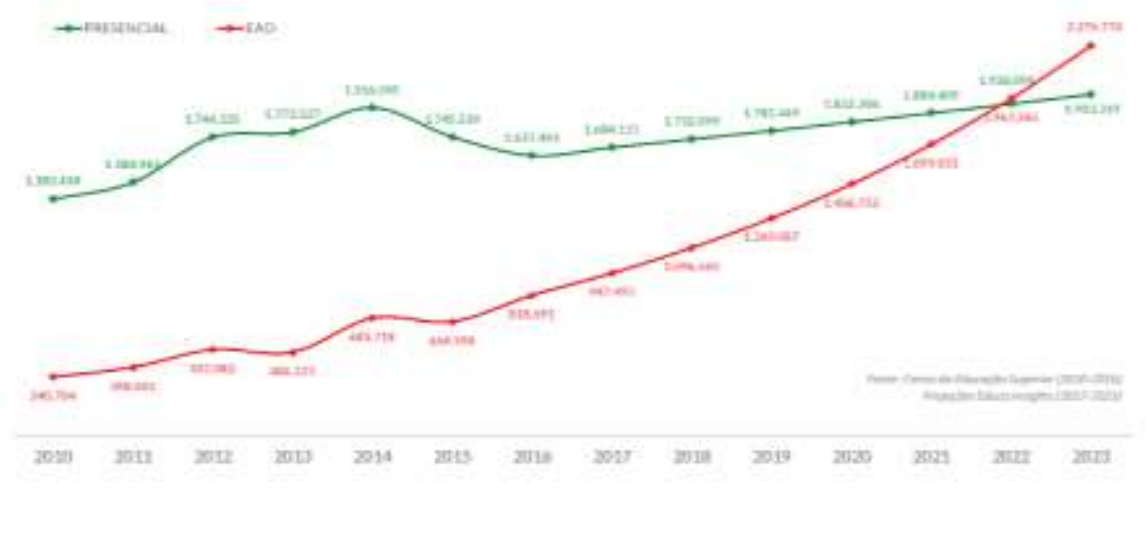

(27) ABMES

Fonte: ABMES e Educa Insights (2020).

Atesta-se que as atividades realizadas com a finalidade de remediar a problemática do COVID-19 não devem ser apropriadas e internalizadas pelas IES como o "novo normal". A pandemia evidenciou o quanto é importante a presença do professor em sala de aula, e de como este é essencial no processo de ensino-aprendizagem, contudo, Verifica-se que quando se fala em educação no pós-pandemia, fala-se mais em implementação e expansão do EAD ou ensino híbrido que em outras problemáticas que estamos enfrentando, tal como se preparar para a retomada, evasão e abandono escolar, desigualdades de acesso aos recursos eletrônicos e virtuais e a saúde mental dos professores e alunos, tal como destacado pelo Banco Mundial (World Bank Grop Education 2020a; 2020b).

O século XXI exige do ensino uma postura mais versátil, não se nega. É preciso reformular a sala de aula para atrair uma geração que se desenvolve tendo o aparelho celular ou tablet como uma extensão de si. O uso de tecnologias de comunicação tem se mostrado uma importante ferramenta de estímulo à autonomia do aluno e à autoaprendizagem. Porém, mostra-se imperioso reafirmar a importância do professor neste processo. O ensino não se consubstancia apenas na absorção de conteúdo, e o docente, além de facilitador da aprendizagem, colabora com a formação do aluno enquanto profissional e cidadão.

Além disso, na modalidade virtual, o método também se apresenta como um elemento do processo de ensino, mas a proposta passa a depender não somente do professor, mas também de o aluno criar hábito do estudo e aprofundar seu conhecimento por meio da pesquisa daquilo que acabou de estudar. Entretanto, é preciso denunciar que os novos métodos de ensino podem propiciar uma nova dinâmica de exploração do professor como profissional. A estrutura online e a carreira de docente virtual caso não seja regulamentada, tende a precarizar a figura do docente. Por exemplo, os materiais elaborados e as aulas gravadas podem ser usadas exaustivamente reproduzidos por anos, sem que o professor receba direitos autorais ou tenha controle sobre a utilização do material. O professor se torna refém da remodelação do ensino.

No caso do ensino do Direito por exemplo, os alunos acabam absorvendo a linguagem jurídica e certos trejeitos do campo, incorporando a partir do contato interpessoal com o professor, aos poucos, os signos das profissões jurídicas, como os 
jargões, as vestimentas, bem como nutrem sonhos e expectativas a partir do "modelo" representado pelo professor. Assim, "os conhecimentos serão esquecidos, mas ficaram outras coisas que, por sua vez, condicionarão atitudes e condutas futuras (Morales, 2006, p.24).

Além disso, uma boa relação com o aluno é importante porque a aceitação afetiva é essencial para que a mensagem tudo aquilo que lhe é transmitido - chegue ao aluno (ou melhor dizendo que ele esteja aberto a recebê-la). A relação professoraluno também pode instrumentalizar motivação ao alunado. Cumpre lembrar, por fim, que os alunos se relacionam entre si, de modo que o professor deve colaborar para tais relações, ensinar habilidades sociais e estratégias de aprendizado cooperativo

\section{Considerações Finais}

Com a Pandemia de COVID-19, teve-se uma migração em larga escala para os ambientes virtuais a fim de viabilizar a manutenção das atividades acadêmicas neste período, porém isso tem intensificado o processo de precarização do professor de nível superior. A inserção de tecnologias digitais vem ocorrendo em diversas IES sem suporte pedagógico ou mudança cultural do processo de ensino-aprendizagem quanto à ressignificação dos papeis das partes, em especial em relação do aluno, o contratante/consumidor que em regra mantém a postura passiva de querer receber conteúdo, o que compreendem como parte do serviço contratado.

A pandemia não só evidenciou impactos da mercantilização do ensino e fez com que eles fossem sentidos de forma mais intensa, como vem produzindo elementos legitimadores. Que fique claro que o objetivo aqui nesta sede não é rechaçar a tecnologia. Ao contrário, esta ferramenta pode potencializar sim os níveis de aprendizagem se forem utilizadas de forma adequada e com a devida preparação/formação do profissional da educação, assim como incentivar o aluno a ir além na sua própria aprendizagem. A tecnologia dever se um meio que potencializa o ensino, e não um fim de corte de custo par aumento do lucro.

Este trabalho buscou construir uma análise do atual cenário, de suas dinâmicas e das dificuldades inerente aos novos tempos do ensino. A pandemia agravou um cenário que se observava de modo insipiente, da precarização da mão de obra docente, que teve de se adaptar sem tempo e sem qualquer preparação prévia para o ensino telepresencial. Na prática, nota-se uma transformação significativa na rotina de trabalho do professor universitário, com sobrecarga de volume de trabalho e de jornada, acompanhadas ainda exaurimento mental, consequências da nova dinâmica do trabalho.

Com isso, propugna possíveis indicações para o futuro uma vez ensino não-presencial é tido como futuridade iminente e defendido pelas entidades ligadas ao setor de ensino privado como novo normal pós-coronavírus.

\section{Referências}

ABMES \& EDUCA INSIGHTS (2020). Coronavirus e Educação Superior: o que pensam alunos e como sua como IES deve se preparar? Website da ABMES < https://abmes.org.br/eventos/detalhe/820>

ANUP (2020). Tipos de Tecnologias educacionais. Ações de apoia às universidades particulares, para uso de tecnologias educacionais. ANUP - Associação Nacional das Universidades Particulares. Tecnologias Educacionais <https://anup.org.br/site/wp-content/uploads/2020/03/Tecnologias_educacionais.pdf >.

Brasil. (2019). Censo da Educação Superior 2018: notas estatísticas. Instituto Nacional de Estudos e Pesquisas Educacionais Anísio Teixeira (Inep).

Cardano, M. (2017). Manual de pesquisa qualitativa. A contribuição da teoria da argumentação. Tradução: Elisabeth da Rosa Conill. Petrópolis, Vozes.

Freire, P. (1987). Paulo. Pedagogia do oprimido. Paz e terra.

Freire. P. (2002). Pedagogia da autonomia: saberes necessários à prática educativa, Paz e Terra.

G1 (2020a) Procon-RJ recebe 500 queixas sobre mensalidades de universidades. 28/04/2020. <https://g1.globo.com/rj/rio-de-janeiro/noticia/2020/04/28/proc on-rj-recebe-queixas-sobre-mensalidades-de-universidades.ghtml>

G1(2020b). Com aulas suspensas durante pandemia, 15 universidades da Bahia são denunciadas ao Procon. 15/05/2020 <https://g1.globo.com/ba/bahia/noticia/2020/05/15/com-aulas-suspensas-durante-pandemia-15-universidades-da-bahia-sao-denunciadas-ao-procon.ghtml> 
Research, Society and Development, v. 10, n. 9, e33810918344, 2021

(CC BY 4.0) | ISSN 2525-3409 | DOI: http://dx.doi.org/10.33448/rsd-v10i9.18344

Agência Brasil, (2020) Procon-SP emite diretrizes para alunos e faculdades particulares. Camila Boehm. <https://agenciabrasil.ebc.com.br/educacao/noticia/2020-05/procon-sp-emite-diretrizes-para-alunos-e-faculdades-particulares>

Indalécio, A. B., \& Ribeiro, M. D. G. M. (2017). Gerações Z e Alfa: os novos desafios para a educação contemporânea. Revista UNIFEV: Ciência \& Tecnologia, 2, 137-148.

Lima, J. P. C., de Abreu, W. F., Poça, H. N. F., Silva, P. C. C., \& Ferreira, A. P. (2019). Financeirização e Oligopolização no Ensino Superior PrivadoMercantil Brasileiro: a sestra e a destra numulárias no âmago da educação. FINEDUCA-Revista de Financiamento da Educação,v. 9.

MEC. Parecer do MEC CNE/CP $n^{\circ}$ 005, de 28 de abril de 2020, aprovado pelo Conselho Pleno do Conselho Nacional de Educação.

Monteiro, M. R. M., \& Pereira, K. T. A. (2018). Educação à distância na era digital: perspectivas para pensar os novos atores virtuais - nativos e imigrantes digitais. Congresso internacional de educação e tecnologias (CIET)

Morales, P. (2008). Relação professor-aluno. Edições Loyola.

Nevado, P. P. (2008). Popper e a investigação: a metodologia hipotética-dedutiva.

Neves, I. D. S. V., \& Fidalgo, F. (2016). Docência e condições de trabalho na ead. SIED: EnPED-Simpósio Internacional de Educação a Distância e Encontro de Pesquisadores em Educação a Distância.

O Valor Da Educação (2020). < http://ovalordaeducacao.com.br/>.

Schlesener, A. H., \& Lima, M. F. (2021). Reflexões sobre a precarização do trabalho docente no Ensino Superior brasileiro. Revista Práxis Educativa, 16.

SEMESP (2020). Posicionamento oficial do SEMESP sobre a redução do valor das mensalidades, 28 de maio de 2020. <https://www.semesp.org.br/noticias/posicionamento-oficial-do-semesp-sobre-a-reducao-do-valor-das-mensalidades/>

World Bank Grop Education (2020a). Políticas Educacionais Na Pandemia Da Covid-19. O que o Brasil pode aprender com o mundo. 8 de abril de 2020. <https://www.todospelaeducacao.org.br/_uploads/_posts/427.pdf?606349279\%20e>

World Bank Grop Education (2020b). Políticas Educacionais Na Pandemia Da Covid-19: O Que O Brasil Pode Aprender Com O Resto Do Mundo? 2 de Abril de 2020. <http://pubdocs.worldbank.org/en/413781585870205922/pdf/POLITICAS-EDUCACIONAIS-NA-PANDEMIA-DA-COVID-19-O-QUE-O-

BRASIL-PODE-APRENDER-COM-O-RESTO-DO-MUNDO.pdf> 